DOI: https://doi.org/10.36502/2021/ASJBCCR.6238

\title{
A Novel Approach for Removal of an Impacted Extraction Balloon Catheter in Common Bile Duct During ERCP- A Case Report
}

\author{
Nauman Idrees ${ }^{1^{*}}$, Srisha Hebbar ${ }^{1}$, Rakesh Sringeri ${ }^{1}$ \\ ${ }^{1}$ Royal Stoke University Hospital, Stoke, United Kingdom
}

Corresponding Author: Nauman Idrees, MBBS, MRCP, FHEA ORCID iD

Address: Royal Stoke University Hospital, Stoke, United Kingdom. Email: nauman.idrees@uhnm.nhs.uk Received date: 26 April 2021; Accepted date: 29 May 2021; Published date: o8 June 2021

Citation: Idrees N, Hebbar S, Sringeri R. A Novel Approach for Removal of an Impacted Extraction Balloon Catheter in Common Bile Duct During ERCP- A Case Report. Asp Biomed Clin Case Rep. 2021 Jun o8;4(2): 103-106.

Copyright (c) 2021 Idrees N, Hebbar S, Sringeri R. This is an open-access article distributed under the Creative Commons Attribution License, which permits unrestricted use, distribution, and reproduction in any medium provided the original work is properly cited.

\begin{abstract}
We describe the case of a 75-year-old female who underwent ERCP for choledocholithiasis. The extraction balloon catheter got impacted at the distal end of a common bile duct (CBD) during attempted stone extraction. Multiple attempts by 2 different ERCP experts to remove the balloon catheter proved unsuccessful. At the time the procedure was carried out, Spyglass Cholangioscopy was not available in the hospital. The balloon catheter was cut outside the channel of scope and used as a nasobiliary drain after an oro-nasal conversion. On repeat ERCP, a few days later, the extraction balloon catheter had fallen out spontaneously into the duodenum. The common bile duct was re-cannulated and stone was successfully removed. This is only the second case report of an impacted extraction balloon catheter in CBD.
\end{abstract}

\section{Keywords}

Endoscopic Retrograde Cholangiopancreatography, Common Bile Duct, Liver Function Tests, Controlled Radial Expansion Balloon, Balloon Catheter, Case Report

\section{Abbreviations}

ERCP: Endoscopic Retrograde Cholangiopancreatography; CBD: Common Bile Duct; LFT's: Liver Function Tests; CRE Balloon: Controlled Radial Expansion Balloon

\section{Introduction}

Common bile duct stones are managed endoscopically in a majority of cases. This is carried out using Endoscopic Retrograde Cholangiopancreatography (ERCP) and CBD stones are removed successfully in $80-90 \%$ of the cases [1]. Stone extraction is usually carried out using the extraction balloon catheter or a dormia basket. ERCP is associated with a 3-5 \% risk of complications including pancreatitis, perforation, bleeding, and aspiration.
There are some case reports of impacted dormia baskets in a common bile duct. We report only the second case in the literature of an impacted extraction balloon catheter in a common bile duct. We have also suggested a novel approach to the management of this very rare complication.

\section{Case Report}

A 75-year-old female presented to the Emergency Department with a four-day history of right upper 
Citation: Idrees N, Hebbar S, Sringeri R. A Novel Approach for Removal of an Impacted Extraction Balloon Catheter in Common Bile Duct During ERCP- A Case Report. Asp Biomed Clin Case Rep. 2021 Jun o8;4(2):103-106.

quadrant pain radiating to the tip of the right shoulder. This was accompanied by nausea. She had a background history of left-sided Ulcerative colitis (in deep remission), Ischaemic heart disease, and Atrial Fibrillation. On clinical examination, she was noted to be mildly jaundiced and tachycardiac with a heart rate of $108 /$ minute. She had mild tenderness in the epigastrium and right upper quadrant with no guarding or rigidity. Her initial blood test showed raised bilirubin of $8.65 \mathrm{mg} / \mathrm{dl}$, alkaline phosphatase of $302 \mathrm{U} / \mathrm{L}$, and Alanine transaminase of $245 \mathrm{IU} / \mathrm{L}$.

An Ultrasound abdomen showed a distended gallbladder with 2 gallstones in it. The common bile duct (CBD) was dilated to $11 \mathrm{~mm}$ but no stones could be seen in the common bile duct. She subsequently underwent an MRCP which showed dilated $\mathrm{CBD}$ of $9 \mathrm{~mm}$ with a distal CBD stone measuring $8 \mathrm{~mm}$ (Fig-1). An ERCP was performed as an inpatient by a Consultant ERCP trainer. The procedure was done under sedation using fentanyl 10omcg and midazolam 3mg. Despite doing a $12 \mathrm{~mm}$ sphincteroplasty after the initial sphincterotomy, the stone could not be removed. Therefore, a 7 French $5 \mathrm{~cm}$ double pigtail plastic stent was placed to allow drainage. A repeat ERCP was planned in 8 weeks' time. The patient completed the course of antibiotics and was discharged home. Her LFTs were repeated a week after discharge. Her LFTs had returned back to baseline and were as follows: Bilirubin 0.70mg/dl, Alanine Transaminase $21 \mathrm{IU} / \mathrm{L}$, ALP $89 \mathrm{U} / \mathrm{L}$, and Albumin $37 \mathrm{~g} / \mathrm{L}$.

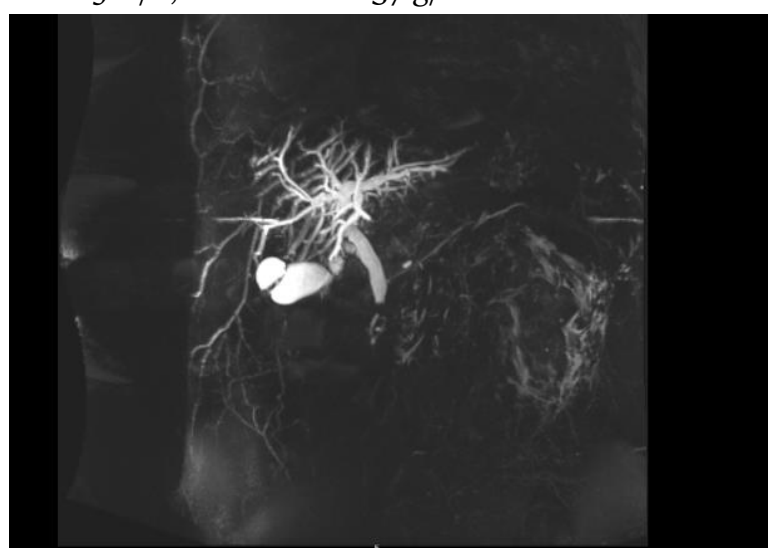

Fig-1: MRCP image with 3 D construction of biliary tract showing stone in Common bile duct

The patient attended for repeat ERCP in 8 weeks' time which was organized as a day case. The procedure was performed by a consultant under sedation with fentanyl 20omcg and midazolam 5mg. The stent was removed using stent graspers, and CBD was subsequently cannulated. The stone was noted on the cholangiogram (Fig-2). Multiple $12 \mathrm{~mm}$ and $13.5 \mathrm{~mm}$

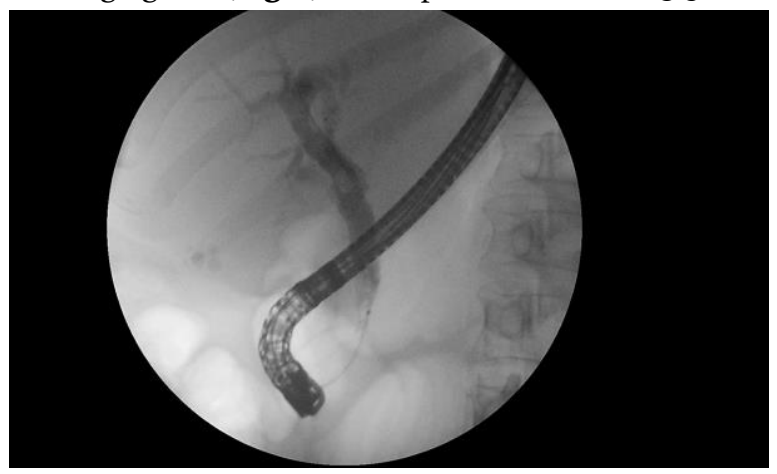

Fig-2: fluoroscopic image showing dilated $\mathrm{CBD}$ and stone in the duct

balloon trawls were performed yielding a small amount of sludge only. During the final cholangiogram, the stone was noted to be at the level of hilum. It was brought down using an inflated extraction balloon catheter. The extraction balloon catheter got impacted at the distal common bile duct (Fig-3). Despite the deflation of the balloon, it could

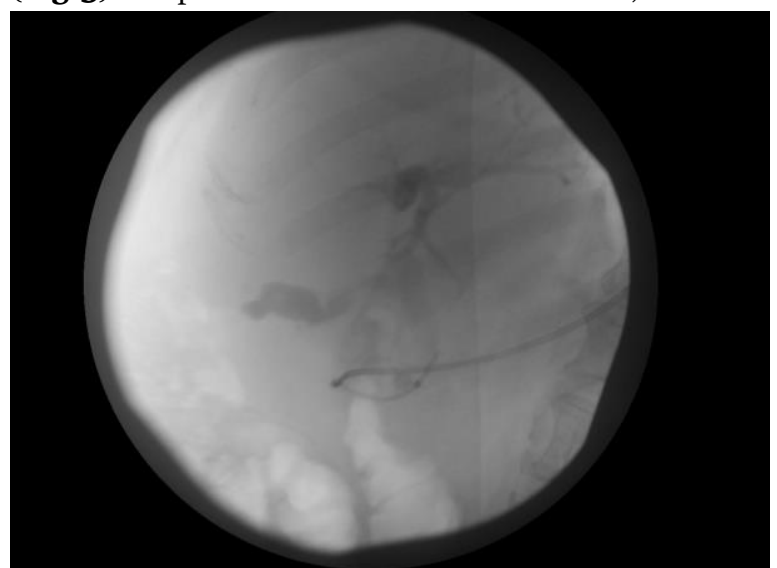

Fig-3: Fluoroscopic image showing impacted balloon catheter.

not be removed. Another ERCP expert was called in to assist who could not retrieve the balloon catheter either. Attempts to cannulate by the side of the balloon catheter using another sphincterotome also failed as no accessory could pass beyond the point where the catheter got impacted in distal CBD (Fig-4). The duodenoscope was removed over the extraction balloon catheter, once the external end of the catheter was cut. Oro-nasal conversion of balloon extraction catheter was done in a similar way to the nasojejunal feeding tube placement. The consultant Endoscopist discussed the patient's management with the surgical 
Citation: Idrees N, Hebbar S, Sringeri R. A Novel Approach for Removal of an Impacted Extraction Balloon Catheter in Common Bile Duct During ERCP- A Case Report. Asp Biomed Clin Case Rep. 2021 Jun o8;4(2):103-106.

\section{Case Report}

team and the patient.

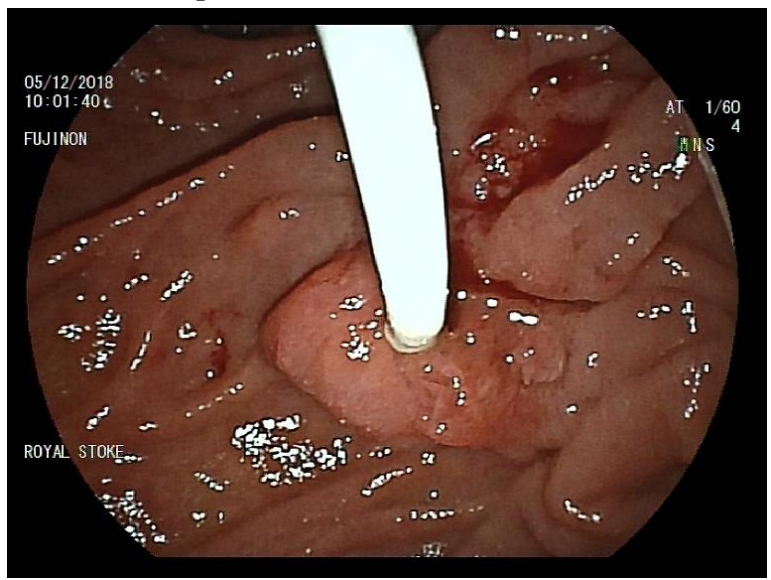

Fig-4: Endoscopic image of impacted balloon catheter

A decision was made to manage it conservatively with a plan to re-attempt ERCP in a few days' time when the inflammation and edema at the distal common bile duct secondary to the procedure have settled down. The patient was admitted to the surgical ward and started on antibiotics with monitoring of nasobiliary drain. The nasobiliary drain drained well and patients' LFTs and infection markers remained stable (Bilirubin 1.05mg/dl, ALP $152 \mathrm{u} / \mathrm{l}$ ) with no fever or abdominal pain. ERCP was repeated 5 days later under deep sedation with propofol. When the duodenoscope was passed down to the second part of the duodenum, the balloon catheter had disengaged spontaneously and fallen into the duodenum. This was removed, and the bile duct was cannulated. Attempts to extract the stone failed again. Therefore, a sphincteroplasty was performed using a $12 \mathrm{~mm} \mathrm{CRE}$ (Controlled radial expansion) balloon. On subsequent balloon trawl, a longitudinal stone was extracted. An occlusion cholangiogram confirmed the common bile duct to be clear (Fig-5). The patient was discharged

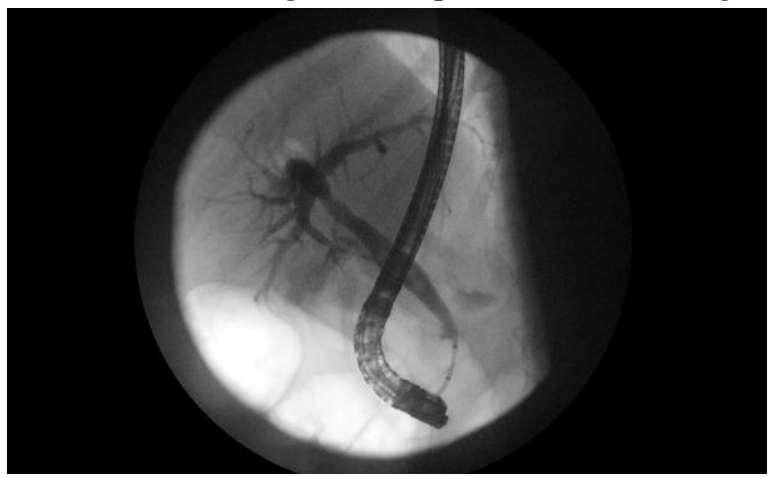

Fig-5: final occlusion cholangiogram after the second ERCP showing duct clear of stones.

home and repeat blood tests done a week later showed normalization of liver function tests with bilirubin of $0.35 \mathrm{mg} / \mathrm{dl}$ and ALP of $63 \mathrm{u} / \mathrm{L}$.

\section{Discussion}

ERCP is an effective technique to remove common bile duct stones. The common bile duct stones are removed using either an extraction balloon catheter or a dormia basket. Several randomized studies have shown that balloon catheter is as effective as dormia basket in achieving ductal clearance [2,3]. This is especially the case for stones measuring $10 \mathrm{~mm}$ or less in size. An uncommon complication with dormia basket is that it can get impacted in the lower end of CBD with an incidence of 0.8 to $5 \cdot 9 \%$ [4-7].

After an extensive literature search, we found only one case of extraction balloon catheter impaction in the CBD. Dr. Saad Ali et al described a case where a patient was transferred to their hospital with impacted extraction balloon catheter [8]. The external part of balloon catheter was coming out of the mouth. They re-intubated the patient with a duodenoscope and assessed the impaction site with a spyglass. They successfully cannulated the CBD with a sphincterotome bypassing the obstruction site. Subsequently, they removed the balloon catheter by pulling on its external part and it was successfully removed.

In our case, we were unable to pass any accessory beyond the blocked balloon catheter, and attempts to remove balloon by pulling on external part of catheter in duodenum with forceps also failed. Spyglass cholangioscopy was unavailable at our centre at the time. We approached this conservatively by cutting the extraction balloon catheter from outside and performing an oro-nasal conversion to use it as a naso biliary drain to achieve drainage. By doing this we were able to give some time for inflammation/oedema around the distal CBD to settle whereby the balloon catheter fell out spontaneously. This approach avoided the need for a major surgical intervention and associated morbidity to the patient. We have described a novel and safe technique for the management of a rare complication of ERCP.

The patient improved clinically and biochemically after the second procedure and was symptom free on 
Citation: Idrees N, Hebbar S, Sringeri R. A Novel Approach for Removal of an Impacted Extraction Balloon Catheter in Common Bile Duct During ERCP- A Case Report. Asp Biomed Clin Case Rep. 2021 Jun o8;4(2):103-106.

\section{Case Report}

discharge. The patient was really pleased to have avoided the surgery and was involved in the decision making process all along.

\section{Competing Interests}

All authors have read and approved the final version of the manuscript. The authors have no conflicts of interest to declare.

\section{References}

[1] Cotton PB. Endoscopic management of bile duct stones; (apples and oranges). Gut. 1984 Jun;25(6):58797. [PMID: 6376290]

[2] Ishiwatari $\mathrm{H}$, Kawakami H, Hisai H, Yane K, Onodera M, Eto K, Haba S, Okuda T, Ihara H, Kukitsu T, Matsumoto R, Kitaoka K, Sonoda T, Hayashi T; Hokkaido Interventional EUS/ERCP Study (HONEST) Group. Balloon catheter versus basket catheter for endoscopic bile duct stone extraction: a multicenter randomized trial. Endoscopy. 2016 Apr;48(4):350-57. [PMID: 26760604]

[3] Ozawa N, Yasuda I, Doi S, Iwashita T, Shimizu M, Mukai T, Nakashima M, Ban T, Kojima I, Matsuda K, Matsuda M, Ishida Y, Okabe $\mathrm{Y}$, Ando $\mathrm{N}$, Iwata $\mathrm{K}$. Prospective randomized study of endoscopic biliary stone extraction using either a basket or a balloon catheter: the BasketBall study. J Gastroenterol. 2017 May;52(5):623-30. [PMID: 27631594]

[5] Ferjaoui W, Chaouech MA, Hmida WB, Bouali R, Ghariani W, Jerraya H, Nouira R. Endoscopic removal of impacted Dormia basket: the post-cut procedure. Gastroenterol Hepatol Endosc. 2019 Aug 05;4:1-2.

[6] Liu W, Zhang LP, Xu M, Zeng HZ, Zeng QS, Chen HL, Liu Q, Tang SJ, Hu B. "Post-cut": An endoscopic technique for managing impacted biliary stone within an entrapped extraction basket. Arab J Gastroenterol. 2018 Mar;19(1):37-41. [PMID: 29519631]

[7] O'Brien JW, Tyler R, Shaukat S, Harris AM. Laparoscopic Common Bile Duct Exploration for Retrieval of Impacted Dormia Basket following Endoscopic Retrograde Cholangiopancreatography with Mechanical Failure: Case Report with Literature Review. Case Rep Surg. 2017;2017:5878614. [PMID: 28785504]

[8] Ali SE, Frandah W, Mardini H, Gabr M. 1692 Retrieval of Impacted Extraction Balloon: A Rare Complication of ERCP for Choledocholithiasis. The American Journal of Gastroenterology. 2019 Oct $1 ; 114:$ S944-45.

Keywords: Endoscopic Retrograde Cholangiopancreatography, Common Bile Duct, Liver Function Tests, Controlled Radial Expansion Balloon, Balloon Catheter, Case Report 